\title{
Could environmental public policy be harmful for the environment?
}

\author{
Mouez Fodha ${ }^{*}$
}

\section{Introduction}

Households' environmental actions were initially limited to the purely personal (protection of homes against noise pollution, lawn and garden maintenance, individual wastewater purification of homes not connected to a collective sewage system), but today are widened to the entire environmental field ${ }^{1}$ : combating biodiversity loss, sorting and recycling waste, fighting air, water, and ground pollution. This increasing engagement of individuals in environmental protection corresponds to an increasing social demand for more and more environmental requirements in the OECD countries.

These shifts have occurred simultaneously with increased environmental spending by the state (see Figure 1). Over the period 1990-2003, household spending for environmental protection has increased on average by $3.5 \%$ per year even though governmental spending has increased by nearly $7 \%$ per year (Ifen, 2005). Thus, according to Ifen (2005), the growth in total expenditure on environmental protection has been between $3 \%$ and $6 \%$ annually, and even approached $10 \%$ in the years 1993-1995. At the same time, GDP only grew in value by an annual average of $2 \%$.

This development poses the problem of the distribution of competences between households and the state. This paper examines the interactions between the voluntary commitments of individuals and state intervention in the field of environmental protection. I am interested particularly in the case where households are involved in environmental protection through a tradeoff between polluting consumption and environmental-quality-improving abatement, alongside a public action conducted by the state to maintain the environment.

* Centre d'Économie de la Sorbonne - University Paris 1, Paris School of Economics, Maison des Sciences Economiques, 106-112 Bld de l'Hôpital, 75647 Paris Cedex, Tel. : +33 (0)1 440782 21, Fax. : +33 (0)1 44 0782 31,E-mail : fodha@univ-paris1.fr

The author is indebted to two anonymous referees for their helpful suggestions and comments on an earlier version of this article. The author is also grateful to the Journal Editor Michel De Vroey and to the participants at the 2007 CREE conference.

1 For data, see Ifen (2006). 
Figure 1 : Environmental spending, France, EUR millions

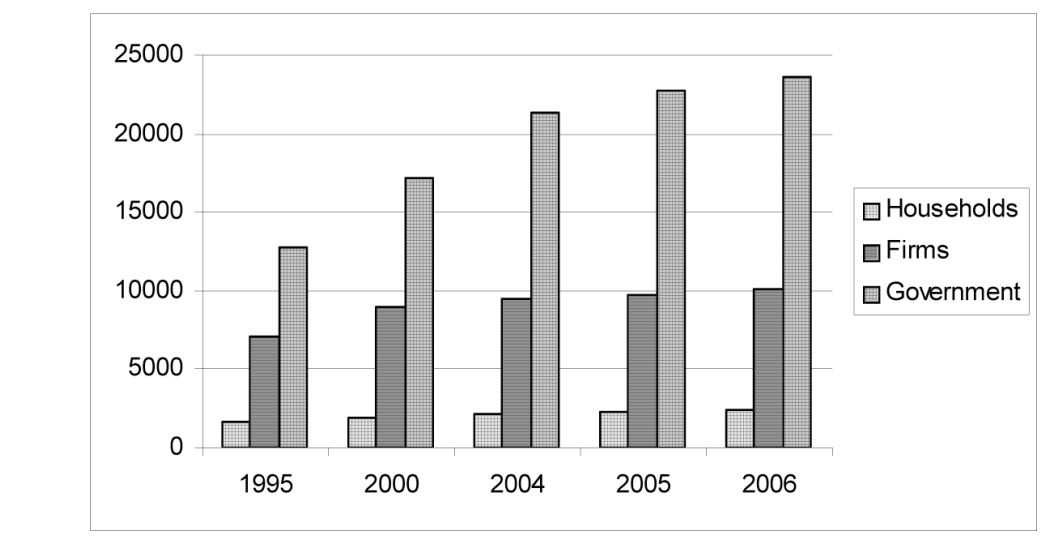

Source: Ifen (2005).

Most previous research on tax policies aiming to finance pollution abatement activities ${ }^{2}$ has adopted a static or intertemporal growth framework. In the static framework, the literature which analyzes public abatement has mainly consisted of a re-examination of double-dividend problems ${ }^{3}$. Allocating revenue from the tax to an environmental benefit raises no uncertainties concerning the occurrence of the second dividend (Bovenberg and van der Ploeg 1994, Ligthart and van der Ploeg 1996). Then, when the economy presents properties of unlimited economic growth, abatement becomes a necessary (but not sufficient) condition for obtaining a win-win situation (van der Ploeg and Withagen 1991, Gradus and Smulders 1993, Michel and Rotillon 1996).

In this paper, I analyze the effects of earmarking a tax for abatement tasks, in a closed-economy framework with overlapping generations and pollution externalities. Taking generations of selfish individuals into account generates intergenerational externalities that, a priori, only the government (or a planner) could put to an end.

My analytical framework is close to that of John and Pecchenino (1994) and John et al. (1995). They studied the consequences of an environmental tax whose revenue finances a public-pollution-abatement activity. They compared the equilibrium properties when choices were conducted by households (or a short-lived government) ${ }^{4}$ and by a planner. The results show that

2 Abatement activity consists of either abatement costs or an explicit abatement sector which needs the allocation of production factors such as capital and labor.

3 The debate over the efficiency of environmental fiscal policy has been revived by the work of Goulder (1995) on the double dividend. At a fixed-budget equilibrium, the implementation (or rise) of an environmental tax can lower another pre-existing tax (on labor, for example): there is a double dividend if the reform leads to an environmental benefit (the first dividend) as well as an economic benefit (the second dividend).

4 The distinction between households and short-lived governments is not evident in these papers. Notably, these studies considered the coexistence of $N$ individuals but did not address the difficulties of non-cooperation 
households, incapable of coordination amongst themselves, play a passive role in environmental protection. These studies also analyzed the potential conflicts between growth and the sustainability of environmental quality in the absence of public intervention. They show that growth of capital and improvement of the environment can be obtained simultaneously ${ }^{5}$. Marini and Scaramozzino (1995) addressed the optimum in which only the government abates pollution. They showed that when the economy is characterized by different coexisting generations, the Samuelson rule must be modified by taking into account a relevant social discounting rate. Jouvet, Michel and Pestieau (2000) and Jouvet, Michel and Vidal (2000) established that taking into account altruistic dynasties, even allowing for dealing with environmental externalities, is not enough to ensure that the competitive equilibrium becomes optimal with voluntary contributions for abatement. Governmental intervention is therefore always necessary.

Nevertheless, in these studies, the public and private choices for abatement are always exclusive, even as environmental concerns and inherent consumer spending become increasingly strong alongside increasing public commitments. My research seeks to determine the role of government in environmental action while individual agents also voluntarily contribute to the fight against pollution.

I consider an economy where, alongside private decisions on abatement, the government levies a lump-sum tax on individual agents and applies the revenue to environmental protection. Public and private abatement activities improve environmental quality in different ways: private abatement repairs damage (curative action), while public intervention preserves the environment (preventative action). In particular, we show that, under precise conditions concerning the technological conditions of abatement, this tax policy can increase the stock of capital as well as the quality of the environment. As a result, depending on the types of inefficiency of the initial steady state (i.e. over- or under-accumulation of capital and over- or under-preservation of the environment) this policy may be Pareto improving. Depending on the configurations, public and private abatement may evolve together or one can be substituted for the other. I also show that the tax does not put an end to the economic-environmental conflicts that exist.

In the first section, I present the assumptions of the model. The next section considers the capital and environmental dynamics and the properties of the steady states. The third section looks at the social optimum in the long term as well as at its decentralization. I present my conclusions in the last section.

among individuals. Free-riding behavior does not exist because the short-lived government dictates actions to households.

5 In addition, the decentralization of the optimum defined by John and Pecchenino (1994) is found in Ono (1996), by means of taxes on consumption (source of pollution). 


\section{The economy}

\subsection{Households ${ }^{6}$}

At each period $t$, a representative agent living for two periods is born. We assume no population growth. Being young, the agent is endowed with one unit of labor that is offered inelastically to firms. His or her wage $w_{t}$ is divided between savings $s_{t}$, pollution abatement contribution $m_{t}$, and tax payments $\tau_{t}$. In the second period, being old, the agent derives utility from his or her consumption $c_{t+1}$ and the quality of the environment $e_{t+1}{ }^{7}$, using his or her savings along with the interest earned at the interest rate $r_{t+1}$. The agent's action in favor of the environment arises from a voluntary choice, with decisions coming from the arbitrage between consumption and abatement in order to benefit from a better environment.

The state applies taxes $\tau_{t}$ to the improvement of environmental quality with a yield that can be different from that from private abatement. These two abatement activities ${ }^{8}$ will only affect the environment in the subsequent period. The quality of the environment $e_{t}$ evolves according to:

$$
e_{t+1}=\left[1-h\left(\tau_{t}\right)\right] e_{t}-\alpha c_{t}+\phi m_{t}
$$

where $\alpha \geq 0$ is the rate of pollution emitted by consumption and $\phi>0$ represents private abatement technology, assumed to be linear (see John et al., 1995). $h\left(\tau_{t}\right)$ is interpreted as a rate of natural degradation ${ }^{9}$ in the quality of the environment. Like van der Ploeg and Withagen (1991) and Beltratti (1995), I assume that the rate is endogenous, depending on the public commitment $\tau$. Thus, $\tau$ slows down the natural degradation of the environment and corresponds as a result to the spending on environmental infrastructure. I assume $h(\tau) \in[0,1]$ with $h(0)=1, \lim _{\tau \rightarrow \infty} h(\tau)=0, h^{\prime} \leq 0$, $h^{\prime \prime}>0$ reflecting diminishing returns of public abatement efforts.

This representation of distinct techniques for the protection of the environment corresponds to many examples. Indeed, following Ifen (2005), it is possible to classify expenditure to protect the environment according to whether they will be, at the end of the day, curative (repairing damage from pollution) or preventative (stopping or reducing pollution at source).

6 My assumptions about households are close to Zhang's (1999).

7 I assume that the household does not consume in the first period. This assumption allows us to consider only the utility in the second period of life as well as looking specifically at the trade-off between consumption and abatement. This hypothesis is also consistent with the assumption that the first period consumption is constant.

8 The assumption of a unique representative agent is a departure from the literature on the private provision of a public good à la Bergstrom et al. (1986). Thus, following the example of John and Pecchenino (1994), we do not consider the distortions from non-cooperation.

9 The rate of degradation $h$ acts like a speed of recovery of the environment at a level incompatible with human activity. 
Household spending is geared primarily toward curative actions (soundproofing, wastewater treatment, waste separation) while public spending is more preventative (air purity protection, protection of biodiversity and the countryside, management of protected areas and species conservation) ${ }^{10}$.

This representation of the quality of the environment (Equation 1) and of the distinct consequences of public $\left(\tau_{t}\right)$ and private $\left(m_{t}\right)$ abatement illustrate, for example, the case of urban pollution and the environmental performance of cities: without specific maintenance, the quality of the urban environment will degrade. Users would then derive less value from public parks, planted pathways, flower gardens, bicycle tracks, etc. Therefore, the municipality supports the preservation of the environment by intervening in its rate of degradation (replacement and maintenance of trees, grass and flowers in public areas, etc.) and households intervene directly themselves (lower quantities of waste by collection and sorting, reduction of gaseous pollutants through investment in power saving appliances and fuel efficient cars, and so on).

The program of agent $i$ born at time $t$ is:

$$
\begin{gathered}
\underset{c_{t+1}, e_{t+1}}{\operatorname{Max}} U\left(c_{t+1}, e_{t+1}\right) \\
\text { s.t. }\left\{\begin{array}{l}
w_{t}=s_{t}+m_{t}+\tau_{t} \\
c_{t+1}=\left[1+r_{t+1}\right] s_{t} \\
e_{t+1}=\left[1-h\left(\tau_{t}\right)\right] e_{t}-\alpha c_{t}+\phi m_{t}
\end{array}\right.
\end{gathered}
$$

with $U\left(c_{t+1}, e_{t+1}\right)$ twice continuously differentiable, strictly concave, with $U_{c}^{\prime}>0, U_{e}^{\prime}>0 \quad \lim _{c \rightarrow 0} U_{c}^{\prime}=+\infty, \lim _{e \rightarrow 0} U_{e}^{\prime}=+\infty, \frac{\partial^{2} U(c, e)}{\partial c \partial e} \geqslant 0$ representing complementarity between consumption and the environmental quality.

Assumption 1 The relative preference for the environment $\varepsilon_{e / c}=\frac{U_{c}^{\prime}}{U_{c}^{\prime}} \frac{e}{c}>0$ is constant ${ }^{11}$.

The first-order conditions define the private arbitrage rule between consumption and maintenance

$$
\frac{U_{c_{t+1}}^{\prime}}{U_{e_{t+1}}^{\prime}}=\frac{\phi}{1+r_{t+1}}
$$

This condition equalizes the marginal substitution rate between consumption and environmental quality and the marginal transformation rate: the level of savings is such that the household is indifferent between con-

10 In the following, I do not distinguish between pollution abatement and protection or maintenance of the environment.

11 This condition on the relative preferences limits the specifications of the utility function to certain welldefined forms. The usual forms (logarithmic, Cobb-Douglas, CRRA) respect this property. For details outlining the consequences, see Gradus and Smulders (1993), Michel and Rotillon (1996) or Zhang (1999). 
sumption and protecting the environment. Households are not altruistic; they do not care about the disutility for future generations caused by the environmental degradation provoked by the current generation's consumption. The rate of pollution $\alpha$, which measures this intergenerational externality, is therefore absent.

\section{$2.2 \quad$ Firms}

There exists one representative competitive firm that maximizes its instantaneous profit. This firm produces a unique numéraire good. I assume CobbDouglas production technology that satisfies the Inada conditions such that $y_{t}=f\left(k_{t}\right)=k_{t}^{\lambda}(0<\lambda<1)$, where $y_{t}$ and $k_{t}$ are production per capita and capital stock per capita, respectively. Capital is fully depreciated within one period. The first order conditions are:

$$
\left\{\begin{array}{l}
f^{\prime}\left(k_{t}\right)=\lambda k_{t}^{\lambda-1}=1+r_{t} \\
f\left(k_{t}\right)-k_{t} f^{\prime}\left(k_{t}\right)=(1-\lambda) k_{t}^{\lambda}=w_{t}
\end{array}\right.
$$

\section{The laissez-faire equilibrium}

This paper only deals with interior solutions ${ }^{12}\left(m_{t}>0\right)$. A competitive equilibrium is defined by a sequence $\left\{k_{t}, c_{t}, w_{t}, r_{t}, m_{t}, s_{t}, e_{t}\right\}_{t=1}^{\infty}$ and a tax $\left\{\tau_{t}\right\}_{t=1}^{\infty}$ with $\left(k_{1}, e_{1}\right)$ such that for all $t=1,2 \ldots$ :

$$
\begin{gathered}
w_{t}=s_{t}+m_{t}+\tau_{t} \\
c_{t+1}=\left(1+r_{t+1}\right) s_{t} \\
w_{t}=(1-\lambda) f\left(k_{t}\right) \\
1+r_{t}=f^{\prime}\left(k_{t}\right) \\
s_{t}=k_{t+1} \\
e_{t+1}=\left[1-h\left(\tau_{t}\right)\right] e_{t}-\alpha c_{t}+\phi m_{t} \\
\left(1+r_{t+1}\right) U_{c_{t+1}}^{\prime}=\phi U_{e_{t+1}}^{\prime}
\end{gathered}
$$

We hence have two dynamics. The capital stock dynamics (CD), follow from the optimality condition of individuals (12) and govern the evolution of capital stock. It gives a relationship between $e_{t+1}$ and $k_{t+1}$ which

12 The corner solutions, corresponding to the choices of not contributing to abatement $\left(m_{t}=0\right)$, are not analyzed. In effect, in this case, all growth of environmental taxation improves, without any ambiguity, the index of quality $e_{t+1}$ On the one hand, while reducing available income, this increase diminishes the savings and therefore consumption; on the other hand, the public intervention in abatement is raised. Imposing the maintenance positivity comes back to putting an upper bound on the $\operatorname{tax}(1-\lambda) f\left(k_{t}\right)-k_{t+1} \equiv \bar{\tau}>\tau_{t}$. 
represents the savings choices of the households. The environmental index dynamics (ED) (11) is determined as a function of the capital stock. Finally, Equation (10) represents the capital market equilibrium.

\subsection{Economic and environmental dynamics}

From the Relations (7), (9) and (10), we can express consumption as a function of capital stock:

$$
c_{t+1}=f^{\prime}\left(k_{t+1}\right) k_{t+1} \equiv c\left(k_{t+1}\right)
$$

with $\frac{\partial c\left(k_{t+1}\right)}{\partial k_{t+1}}=\lambda f^{\prime}\left(k_{t+1}\right)>0$ : the savings of one period increase the consumption of the following period. Similarly, since $\frac{\partial c\left(k_{t+1}\right)}{\partial f^{\prime}\left(k_{t+1}\right)}>0$ the effect of substitution is dominant.

Equations (6), (8), (10) fix the choice of the level of abatement:

$$
m_{t}=(1-\lambda) f\left(k_{t}\right)-k_{t+1}-\tau_{t} \equiv m\left(k_{t+1}, k_{t}, \tau_{t}\right)
$$

The changes in environmental quality (ED) can be derived from equation 11 as:

$$
\begin{aligned}
e_{t+1} & =\left[1-h\left(\tau_{t}\right)\right] e_{t}-\alpha \lambda k_{t}^{\lambda}+\phi\left[(1-\lambda) k_{t}^{\lambda}-k_{t+1}-\tau_{t}\right] \\
& \equiv \varphi\left(k_{t+1}, k_{t}, e_{t}, \tau_{t}\right) \quad(\mathrm{ED})
\end{aligned}
$$

This relation entails the following properties: $(i) \frac{\partial \varphi(.)}{\partial k_{t+1}}=-\phi<0$ so that if the savings increase in $t$, all other things being equal, the proportion of resources allotted to private abatement declines, which degrades environmental quality in time $t+1 ;(i i) \frac{\partial \varphi(.)}{\partial \tau_{t}}=-h^{\prime}\left(\tau_{t}\right) e_{t}-\phi \gtreqless 0$ so that the increase in taxes diminishes the amount allotted to private abatement but augments the level of public abatement, and the effect on the environment is therefore indeterminate; $(i i i) \frac{\partial \varphi(.)}{\partial k_{t}}=f^{\prime}\left(k_{t}\right)(\phi(1-\lambda)-\alpha \lambda) \gtreqless 0$, so that an increase in capital stock yields a rise in wages and also a rise in consumption and private abatement levels. This rise in capital in $t$ improves the quality of the environment in $t+1$ (i.e. $\left.\frac{\partial \varphi(.)}{\partial k_{t}}>0\right)$ if, at time $t$, marginal private abatement is higher than marginal degradation of the environment induced by the increase in consumption. This condition holds if $\frac{\phi}{\alpha}>\frac{\lambda}{1-\lambda}$ I assume this condition to be true. Indeed, it suffices that the net flow of pollution is less 
than private abatement in the case where households contribute their entire wage to abatement (under Conditions (7) to (10), $\frac{\phi}{\alpha}>\frac{\lambda}{1-\lambda}$ is equivalent to $\left.\phi w_{t}>\alpha c_{t}\right)^{13}$.

Assumption $2 \frac{\phi}{\alpha}$ is greater than $\frac{\lambda}{1-\lambda}$

The dynamics of the capital stock (CD) comes from the arbitrage conditions of agents and is determined by an implicit relation between $k_{t+1}$ and $e_{t+1}$ :

$$
\begin{aligned}
\left(1+r_{t+1}\right) \frac{\partial U}{\partial c_{t+1}} & =\phi \frac{\partial U}{\partial e_{t+1}} \\
& \Longleftrightarrow e_{t+1}=\varepsilon_{e / c} \phi k_{t+1} \equiv \Phi\left(k_{t+1}\right)
\end{aligned}
$$

with $\Phi^{\prime}\left(k_{t+1}\right)=\varepsilon_{e / c} \phi \geq 0$. Thus households choose their consumption and abatement level such that an increase in capital stock is associated with an increase in environmental quality.

\subsection{Long-term steady-state}

Let us denote the set of steady states by $(\bar{e}, \bar{k})$. This set is defined by the intersection of the curves (ED) and (CD) evaluated in $(\bar{e}, \bar{k})$ and represented by the curves $\bar{e}=\varphi(\bar{k})$ and $\bar{e}=\Phi(\bar{k})$.

From Equation 14 we have that the curve $\bar{e}=\varphi(\bar{k})$ is such that:

$$
\bar{e}=\frac{1}{h(\tau)}\left\{\phi[(1-\lambda) f(\bar{k})-\bar{k}-\tau]-\alpha f^{\prime}(\bar{k}) \bar{k}\right\}
$$

It has the following properties:

$$
\frac{\partial \varphi(\bar{k})}{\partial \bar{k}}=-\frac{1}{h(\tau)}\left\{\lambda \alpha f^{\prime}(\bar{k})+\phi\left[1-(1-\lambda) f^{\prime}(\bar{k})\right]\right\} \gtreqless 0
$$

Taking the derivative of Expression (17), we find:

$$
\frac{\partial^{2} \varphi(\bar{k})}{\partial \bar{k}^{2}}=-\frac{1}{h(\tau)} f^{\prime \prime}(\bar{k})[\lambda \alpha-\phi(1-\lambda)]<0
$$

13 Actually, as noticed by a referee, this assumption is quite optimistic regarding the efficiency of private abatement. Indeed, given that $\lambda$ is usually about $1 / 3$, it means that private environmental expenditures must be more than twice as productive as the negative effect of consumption. But this assumption makes sense in the light of the fact that $\frac{\phi}{\alpha}>\frac{\lambda}{1-\lambda}$ is equivalent to $\phi w-\alpha c>0$. This finally implies that, if the wages of the younger generations were totally devoted to private abatement, the net effect on the environmental quality would be positive, whatever the level of consumption of the older generation. 
Figure 2: Some examples of the set of steady states

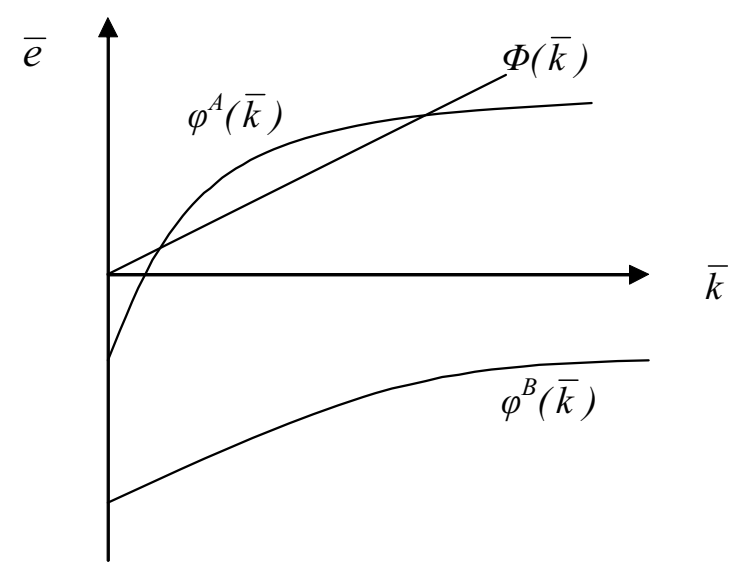

Under Assumption 2, $\frac{\partial \varphi(.)}{\partial k_{t}}>0$ gives $\frac{\partial^{2} \bar{\varphi}(\bar{k})}{\partial \bar{k}^{2}}<0$. Therefore, $\bar{e}=\varphi(\bar{k})$ is concave and possesses the following properties:

$$
\frac{\partial \varphi(\bar{k})}{\partial k} \gtreqless 0 ; \frac{\partial^{2} \varphi(\bar{k})}{\partial \bar{k}^{2}}<0 ; \varphi(0)=-\frac{\phi \tau}{h(\tau)} \leq 0
$$

Let $\bar{e}=\Phi(\bar{k})$ be determined by Equation 15 (CD) such that:

$$
\bar{e}=\Phi(\bar{k})=\varepsilon_{e / c} \phi \bar{k}
$$

This gives $\frac{\partial \Phi(\bar{k})}{\partial k}=\varepsilon_{e / c} \phi>0$ and $\Phi(0)=0$. This relation is linear and strictly increasing.

The set of steady states is the set of points $(\bar{e}, \bar{k})$ such that $\varphi(\bar{k})=\Phi(\bar{k})$. Based on the properties established above (one strictly concave relation and the other linear and strictly increasing), there are generically ${ }^{14}$ two $\left(\varphi^{A}\right)$ stationary equilibria or none $\left(\varphi^{B}\right)$ (see Figure 2).

Proposition 1 Under Assumptions 1 and 2, for a given level of public taxation $\tau$, there exists a locally stable stationary equilibrium $(\bar{e}, \bar{k})$ if and only if the relative preference for the environment is sufficiently high:

$$
\varepsilon_{e / c}>-\frac{1}{\phi h(\tau)}\left\{\lambda \alpha f^{\prime}(\bar{k})+\phi\left[1-(1-\lambda) f^{\prime}(\bar{k})\right]\right\} .
$$

Proof 1 From Equation 14 and 15, the capital dynamics is summarized by: $\Phi\left(k_{t+1}\right)=\left[1-h\left(\tau_{t}\right)\right] \Phi\left(k_{t}\right)-\alpha f^{\prime}\left(k_{t}\right) k_{t}+\phi\left[(1-\lambda) f\left(k_{t}\right)-k_{t+1}-\tau_{t}\right](19)$

14 It is possible that a unique equilibrium that corresponds to a tangent point between $\varphi(\bar{k})$ and $\Phi(\bar{k})$ exists, but this case is a degenerate one that is not considered here. 
The linearization around the stationary state gives ${ }^{15}$ :

$$
d k_{t+1}=\frac{[1-h(\tau)] \Phi^{\prime}(\bar{k})-[\alpha \lambda-\phi(1-\lambda)] f^{\prime}(\bar{k})}{\Phi^{\prime}(\bar{k})+\phi} d k_{t} .
$$

Thus, the equilibrium is stable if and only if $\frac{[1-h(\tau)] \Phi^{\prime}(\bar{k})-[\alpha \lambda-\phi(1-\lambda)] f^{\prime}(\bar{k})}{\Phi^{\prime}(\bar{k})+\phi}<1$ i.e.

$$
-\frac{1}{h(\tau)}\left\{\lambda \alpha f^{\prime}(\bar{k})+\phi\left[1-(1-\lambda) f^{\prime}(\bar{k})\right]\right\}<\Phi^{\prime}(\bar{k})
$$

By Equation 17, the left-hand side of the inequality corresponds to $\frac{\partial \bar{\varphi}(\bar{k})}{\partial \bar{k}}$. Thus the condition of stability is always verified if and only if, at the steady state, $\frac{\partial \bar{\varphi}(\bar{k})}{\partial \bar{k}}<\frac{\partial \bar{\Phi}(\bar{k})}{\partial \bar{k}} \Leftrightarrow-\frac{1}{h(\tau)}\left\{\lambda \alpha f^{\prime}(\bar{k})+\phi\left[1-(1-\lambda) f^{\prime}(\bar{k})\right]\right\}<\varepsilon_{e / c} \phi$.

The stability of the equilibrium $(\bar{k}, \bar{e})$ is thus determined by the respective slopes of the curves $\bar{\varphi}(\bar{k})$ and $\bar{\Phi}(\bar{k})$. In Figure 2, when there are two stationary equilibria (for $\varphi^{A}(\bar{k})$ ) the one for which $\bar{k}$ is the largest is locally stable.

\subsection{Tax policy}

When analyzing the consequences of tax policy on a locally stable steady state, we assume that Condition (20) is true. From Equation 19, let the steady state defined by $\bar{k}$ fulfil:

$$
h(\tau) \Phi(\bar{k})+\alpha f^{\prime}(\bar{k}) \bar{k}-\phi[(1-\lambda) f(\bar{k})-\bar{k}-\tau]=0 .
$$

Using the implicit functions theorem, we find that:

$$
\frac{\partial \bar{k}}{\partial \tau}=-\frac{h^{\prime}(\tau) \Phi(\bar{k})+\phi}{h(\tau) \Phi^{\prime}(\bar{k})+\alpha \lambda f^{\prime}(\bar{k})-\phi\left[(1-\lambda) f^{\prime}(\bar{k})-1\right]} .
$$

The sign of the denominator depends on the term $-\left[(1-\lambda) f^{\prime}(\bar{k})-1\right]$ representing the marginal effect of an increase in capital stock on private abatement $m_{k}^{\prime}=\frac{\partial w(\bar{k})}{\partial k}-\frac{\partial s(\bar{k})}{\partial k} \gtreqless 0$. The result is a priori ambiguous because of the two opposite effects. On the one hand, the increase in savings, and thus in consumption, implies a decline in private abatement; on the other hand the increase in wage leads to an increase in private abate-

15 Although the dynamic system is of one dimension, as pointed out by a referee, the non-linearity imposes an additional condition on the higher-order derivatives: they must be weak or negligible. The linearization is thus pertinent to the stability of the model. This condition demandes, like Proposition 1, that the relative preference for the environment is sufficiently large. In the following, we assume that this condition is true. 
ment (and consumption). Nevertheless, we note that under the sufficient condition for stability (Equation 20), the denominator is strictly positive.

Recall that consumption always increases with capital stock. Thus, any increase in $k$ implies an increase in consumption, thus improving nonenvironmental welfare. This property permits us to associate the variation of capital stock and non-environmental dividends (the second dividend). If, in addition, the tax policy improves environmental quality (defined as a first dividend), a double dividend is attained. comes to

The effect on capital stock is positive $\left(\frac{\partial \bar{k}}{\partial \tau}>0\right)$ if $-\frac{h^{\prime}(\tau) \Phi(\bar{k})}{\phi}>1$ which
to

$$
\bar{k}>-\frac{1}{h^{\prime}(\tau) \varepsilon_{e / c}} .
$$

The effect on the environment can be determined through Equation 16:

$$
\frac{\partial \bar{e}}{\partial \tau}=\frac{\frac{\partial \bar{k}}{\partial \tau}\left\{\phi\left[(1-\lambda) f^{\prime}(\bar{k})-1\right]-\alpha \lambda f^{\prime}(\bar{k})\right\}-\phi}{h(\tau)}-\frac{h^{\prime}(\tau)}{h(\tau)} \bar{e} .
$$

Using Relation (22), this condition becomes:

$$
\frac{\partial \bar{e}}{\partial \tau}=\varepsilon_{e / c} \phi \frac{\partial \bar{k}}{\partial \tau}
$$

which also confirms that the economy moves along Equation 18.

Proposition 2 At a stable steady state, any increase in public abatement increases capital stock and the quality of the environment if and only if $\bar{k}>-1 / h^{\prime}(\tau) \varepsilon_{e / c}$.

Under Condition (23), the marginal increase in taxes, and thus the public abatement, diminishes the flow of pollution at a greater level than private abatement. Following an increase in the tax, households decrease their expenditure on private abatement in favor of investment in capital. Thus, they augment their savings and their consumption, and delegate the activity of abatement to the government. Moreover, under Condition (24), the quality of the environment improves, emphasizing the decline in private abatement. This condition is all the more likely if the economy is at equilibrium with high capital stock and/or public spending on abatement is initially high.

However, at this laissez-faire steady state, agents do not consider the pollution handed down to future generations. They care only for their own welfare: they know that taxation will improve, in a more effective manner than private efforts, the environmental quality and therefore permit them to increase consumption. Thus, the state has the burden of pollution management because its returns are higher than those of private abatement. 
On the other hand, when Condition (23) is not true, public intervention degrades the environment, in part because the increase in taxation discourages private abatement by reducing the revenue available, and in part because the return from public abatement is less effective than the private one, which means it cannot compensate for the reduction.

Let $(\bar{k}, \bar{e})$ be the allocation of the modified golden rule when the planner assigns the same weight to all generations. This allocation is defined by the Samuelson rule and permits the attainment of maximum utility on the set of pairs of decisions $(m, c)$, that verify the constraint on the resources of the economy. Taking up the analysis of John and Pecchenino (1994) again, we know that the competitive equilibrium can be characterized by four inefficiency positions, depending on whether the economy is experiencing over- or under-accumulation of capital ( $\bar{k}>$ or $<\bar{k}$ ), and over- or under-preservation of the environment $(\bar{e}>$ or $<\bar{e}))$.

Proposition 3 At a stable steady state, if the economy is in a position of under-accumulation of capital and under-preservation of the environment, then an increase in public abatement is Pareto improving if and only if $\bar{k}>-1 / h^{\prime}(\tau) \varepsilon_{e / c}$.

Relation (24) indicates that capital and environment move in the same direction. Thus, under Condition (23), an increase of public expenditure increases both capital, savings and consumption (the economic dividend) and the quality of the environment (the environmental dividend).

More precisely ${ }^{16}$, the increase in taxes and public abatement is initially composed of two opposite effects. First, the increase in $\tau$ implies, all other things being equal, an improvement in the quality of the environment $e$. Therefore, the generation affected by this increase in taxation devotes fewer resources to abatement for maintaining the environmental quality from which they will profit in the second period of life. They can then save a larger portion of their income, so accumulating more capital. Second, the increase in $\tau$ diminishes the revenue available to households and therefore their savings, which slows accumulation of capital. But, under Condition (23), public spending is more effective: the increase in $\tau$ permits households to decrease $m$ by a larger amount than the change in $\tau$, which permits them to increase savings and thus capital stock. The increase in capital therefore accompanies an improvement in the quality of the environment, which explains the double dividend.

Moreover, if the economy is in a situation of under-accumulation of capital and under-preservation of the environment, this environmental policy moves the economy closer to its optimum. In this case, public abatement substitutes for private abatement.

\footnotetext{
16 I would like to thank a referee who suggested this interpretation of the mechanisms to me.
} 
If, on the contrary, Condition (23) is not true, the tax decrease automatically increases private abatement, savings, and thus capital stock thanks to a revenue effect. Households must then take responsibility for abatement, substituting for the government.

Corollary 1 At a stable steady state, if the economy is in a position of over-accumulation of capital and over-preservation of the environment, then a decrease in public abatement is Pareto improving if and only if $\bar{k}>-1 / h^{\prime}(\tau) \varepsilon_{e / c}$.

In the context of the over-accumulation of capital and over-preservation of the environment, the government must reduce savings and total abatement efforts. In a manner symmetric to the preceding proposition, when Condition (23) is respected, the state must reduce its intervention by reducing taxes and public abatement, which causes a reduction in capital stock. Households then have lower incomes, despite the tax cuts, since wages fall too. In this case, public and private abatement must decline simultaneously.

Proposition 2 and its corollary concern the necessary condition on the efficiency of environmental policy, which itself takes the form of an increase or a decrease in the public commitment. The analysis of welfare that is conducted here is limited to long-term effects, i.e. to steady states. Taking into account the set of coming generations puts the efficiency of this public intervention into perspective; in fact, depending on the extent of the variation of public commitment, it is possible to switch from one position of inefficiency to another.

Proposition 4 At a stable steady state, if the economy is in a position of over or under-accumulation of capital and under-or over-preservation of the environment, there is a conflict between the search for optimality, the economic dividend and the environmental dividend, whatever the nature of tax policy.

When capital stock and environmental quality change in opposite directions, Relation (24) indicates that the proposed fiscal policy is irrelevant to bringing the economy to its long-term optimum. Indeed, in order to converge, it is necessary to reduce (or increase) capital stock, which implies first reducing (or increasing) consumption and second reducing (or increasing) environmental quality. This result is counter-intuitive and runs counter to previous research on inefficiency dynamics, but results from the existence of a long-term environmental optimum. 


\section{$4 \quad$ Stationary optimal equilibrium}

Consider a planner who maximizes the discounted utilities of the set of all generations. Let $\theta$ be the social discount rate $0<\theta<1$. The program of the social planner is:

$$
\begin{gathered}
\underset{\left\{c_{t}, e_{t}, k_{t}, m_{t-1}, \tau_{t-1}\right\}_{t=1}^{+\infty}}{\operatorname{Max}} \sum_{t=1}^{\infty} \theta^{t-1} U\left(c_{t}, e_{t}\right) \\
\text { s.t. }\left\{\begin{array}{l}
k_{t}=f\left(k_{t-1}\right)-c_{t-1}-m_{t-1}-\tau_{t-1} \\
e_{t}=\left[1-h\left(\tau_{t-1}\right)\right] e_{t-1}-\alpha c_{t-1}+\phi m_{t-1} \\
m_{t} \geqslant 0 ; \tau_{t} \geqslant 0 \\
k_{0}>0, e_{0}>0 \text { given }
\end{array}\right.
\end{gathered}
$$

The derivatives of the Lagrangian with respect to its arguments give the necessary conditions:

$$
\left\{\begin{array}{l}
\frac{\partial L}{\partial c_{t}}=\theta^{t-1} U_{c_{t}}^{\prime}-\theta^{t} \alpha U_{e_{t+1}}^{\prime}-\theta^{t} \lambda_{1, t}-\theta^{t+1} \lambda_{2, t+1} \alpha=0 \\
\frac{\partial L}{\partial m_{t-1}}=\theta^{t-1} \phi U_{e_{t}}^{\prime}-\theta^{t-1} \lambda_{1, t-1}+\theta^{t} \phi \lambda_{2, t}+\theta^{t-1} \lambda_{3, t-1}=0 \\
\frac{\partial L}{\partial k_{t}}=-\theta^{t-1} \lambda_{1, t-1}+\theta^{t} \lambda_{1, t} f^{\prime}\left(k_{t}\right)=0 \\
\frac{\partial L}{\partial e_{t-1}}=\theta^{t-1}\left[1-h\left(\tau_{t-1}\right)\right] U_{e_{t}}^{\prime}-\theta^{t-1} \lambda_{2, t-1}+\theta^{t} \lambda_{2, t}\left[1-h\left(\tau_{t-2}\right)\right]=0 \\
\frac{\partial L}{\partial \tau_{t-1}}=-\theta^{t-1} h_{\tau}^{\prime} e_{t-1} U_{e_{t}}^{\prime}-\theta^{t-1} \lambda_{1, t-1}-\theta^{t} \lambda_{2, t} h_{\tau}^{\prime} e_{t-1}+\theta^{t-1} \lambda_{4, t-1}=0 \\
\lambda_{3, t-1} m_{t-1}=0 \\
\lambda_{4, t-1} \tau_{t-1}=0
\end{array}\right.
$$

with $\lambda_{2, t}$ the implicit price of environmental quality. $\lambda_{3, t}$ and $\lambda_{4, t}$ are the Lagrangian multipliers associated to the constraints of non-negativity of public and private abatement. $-\theta^{t} \alpha U_{e_{t+1}}^{\prime}$ is the marginal disutility actualized at $t+1$ (via the degradation of environmental quality) resulting from consumption at $t c_{t} ;-\theta^{t+1} \lambda_{2, t+1} \alpha$ is the effect of consumption at $t$ on environmental quality at $t+1$.

Suppose a steady state exists in which the contributions and maintenance are strictly positive: $\lambda_{3, t}=0$ and $\lambda_{4, t}=0$. The conditions are:

$$
\begin{gathered}
\frac{\partial L}{\partial c}=U_{c}^{\prime}-\theta \alpha U_{e}^{\prime}-\theta \lambda_{1}-\theta^{2} \lambda_{2} \alpha=0 \\
\frac{\partial L}{\partial m}=\phi U_{e}^{\prime}-\lambda_{1}+\theta \phi \lambda_{2}=0 \\
\frac{\partial L}{\partial k}=-\lambda_{1}+\theta \lambda_{1} f^{\prime}(k)=0
\end{gathered}
$$




$$
\begin{gathered}
\frac{\partial L}{\partial e}=[1-h(\tau)] U_{e}^{\prime}-\lambda_{2}+\theta \lambda_{2}[1-h(\tau)]=0 \\
\frac{\partial L}{\partial \tau}=-h_{\tau}^{\prime} e U_{e}^{\prime}-\lambda_{1}-\theta \lambda_{2} h_{\tau}^{\prime} e=0 .
\end{gathered}
$$

Equation (27) fixes the capital stock per capita at its modified golden rule level $\hat{k}$ :

which gives:

$$
f^{\prime}(\hat{k})=\frac{1}{\theta}
$$

$$
\hat{k}=(\theta \lambda)^{\frac{1}{1-\lambda}} .
$$

Moreover, Equation (28) determines the shadow cost of pollution:

$$
\lambda_{2}=\frac{[1-h(\tau)] U_{e}^{\prime}}{1-\theta[1-h(\tau)]}>0
$$

and Equations (26) and (30) give the shadow price of capital:

$$
\lambda_{1}=\frac{\phi}{1-\theta[1-h(\tau)]} U_{e}^{\prime}>0 .
$$

Finally, by substitution of Equations (30) and (31) in Condition (25), we obtain:

$$
\frac{U_{c}^{\prime}}{U_{e}^{\prime}}=\frac{(\alpha+\phi) \theta}{1-\theta[1-h(\tau)]} .
$$

This rule of arbitrage corresponds to the optimality condition for provision of a public good (Samuelson's condition): the marginal rate of substitution between consumption and the environment is equal to the marginal rate of transformation; by this means, the planner internalizes the externalities of consumption ${ }^{17}$.

Using Equations (29), (30), (31) gives:

$$
-h_{\tau}^{\prime} \hat{e}=\phi \text {. }
$$

Proposition 5 Optimal public abatement $\tau$ is fixed at a level such that there is equality between the marginal productivity of the two abatement activities.

We thus find the property of the optimal tax rates: the marginal excess burden must be zero so that any marginal change leaves welfare unchanged.

17 When the planner considers all generations with equal weight $(\theta=1)$, without public abatement, the conditions of John and Pecchenino (1994) and John et al. (1995) are regained: $\frac{U_{c}^{\prime}}{U_{e}^{\prime}}=\frac{\alpha+\phi}{h}$ and $f^{\prime}(\hat{k})=1$ 
In the next section, we determine the tax system permitting the decentralization of the social optimum, under the assumption that the amount of public abatement is kept by the government at its optimum level.

\subsection{Decentralization of the optimum}

The decentralization of the optimum must internalize three sources of inefficiency: (i) the externality of pollution generated by consumption; (ii) the distortion from the provision of a public good; and (iii) the over- or underaccumulation of capital resulting from the self-interested actions of households.

To these three objectives, the government associates three taxes: a tax on savings $\tau^{k}$ in order to internalize the externality of pollution not taken into account in the arbitrage of agents (taxing savings corresponds to taxing consumption); a tax on wages $\tau^{w}$ needed to reach the optimal level of capital stock; and public expenditure $\hat{\tau}$ intended to accomplish the environmental objective $\hat{e}$. Thus, the optimal tax structure $\left(\hat{\tau}_{w}, \hat{\tau}_{k}, \hat{\tau}\right)$ is determined by the relations:

$$
\begin{gathered}
s\left(\hat{\tau}_{w}, \hat{\tau}_{k}, \hat{\tau}, \hat{T}\right)=\hat{k} \\
\frac{\phi}{\left(1-\tau_{k}\right) f^{\prime}(\hat{k})}=\frac{(\alpha+\phi) \theta}{1-\theta[1-h(\hat{\tau})]} \\
-h_{\tau}^{\prime} \hat{e}=\phi .
\end{gathered}
$$

For instance, the arbitrage condition between consumption and private abatement must be equal to that fixed by the planner (Equation 35). This condition determines the tax on the return of savings:

$$
\hat{\tau}_{k}=\frac{\frac{\alpha}{\phi}+[1-h(\hat{\tau})] \theta}{\frac{\alpha}{\phi}+1}>0
$$

This tax is always positive because $h(\tau) \in[0,1]$ It becomes higher as the net externality $(\alpha / \phi)$ gets larger. Nevertheless, note that public intervention reduces the environmental externality and as a result diminishes the tax rate. 
Figure 3 : Environmental public expenditure to output (OECD, 2006)

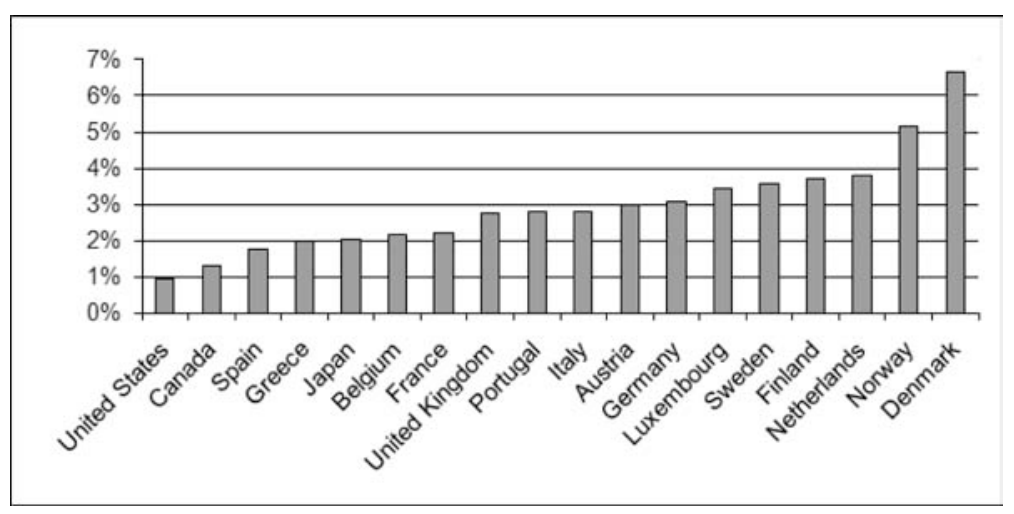

\subsection{Numerical example}

In order to compare these results to the environmental policies implemented in the OECD countries, the economy was calibrated using the following specifications. The function $h($.$) that measures the rate of natural degra-$ dation of the environment is given by $h(\tau)=1 /(1+\tau)$. The relative preference for the environment $\left(\varepsilon_{e / c}\right)$ is set at $5^{18}$. The production function parameter was set at $\lambda=0.3$. Turning to the environmental parameters, the values of the rate of pollution emission and the rate of pollution abatement were set at $\alpha=0.2$ and $\phi=0.1$, respectively. Finally, an equal weight was allocated to all generations, $\phi=0.1$. So specified, the stationary optimum is defined by the set $\{\hat{k}, \hat{y}, \hat{e}, \hat{\tau}\}$ such that $\hat{k}=0.18, \hat{y}=0.59, \hat{e}=0.08, \hat{\tau}=0.05$. The ratio of public expenditure on the environment to the level of output $(\hat{\tau} / \hat{y})$ was then calculated.

This optimal ratio (equal to $9.5 \%$ ) was compared to its observed value the in principle countries of the OECD. The ratio was calculated for 2003. Public expenditure was estimated using the per capita revenue of taxes related to the environment (source OCDE, 2006), that correspond to our definition of $\tau$. The results are given in Figure 3 .

This simple illustration shows that the OECD countries had not reached the optimal ratio of public spending for the environment in 2003 . It is necessary to put this statement in perspective, because I have assumed equal parameter values for all countries in calculating the optimal ratio. I have therefore assumed that there exists only one optimum no matter

18 There is no consensus data for this parameter. This value is dictated to us by (i) the necessary condition for stability (see Proposition 1) and (ii) by the necessities of calibrating our theoretical economy because we do not consider any scale parameter. 
which country is considered, which is a strong assumption. Nevertheless, as shown in Figure 4, I have fixed this value at a pessimistic level corresponding to relatively low public spending. All variation in the value of one or the other parameter would, probably, increase the optimum value of this ratio.

The changes in the optimal ratio $(\hat{\tau} / \hat{y})$ in the economy can be determined as a function of the fundamental parameters (figure 4). This ratio is a decreasing function of the three parameters. In fact, all decreases in $\lambda$ reduce the optimal production and thus reduce all income; increasing $\theta$, giving a more important weight to future welfare, encourages households to be more concerned about protecting the environment, which permits the government to reduce its commitment; finally, the same reasoning explains the link between the ratio $(\hat{\tau} / \hat{y})$ and the preference for the environment $\varepsilon_{e / c}$ : the higher this parameter the more agents contribute voluntarily to the environment.

Figure $4: \hat{\tau} / \hat{y}$ as $\lambda(-), \theta(--)$ and $\varepsilon_{e / c}(\mathrm{x})$ change

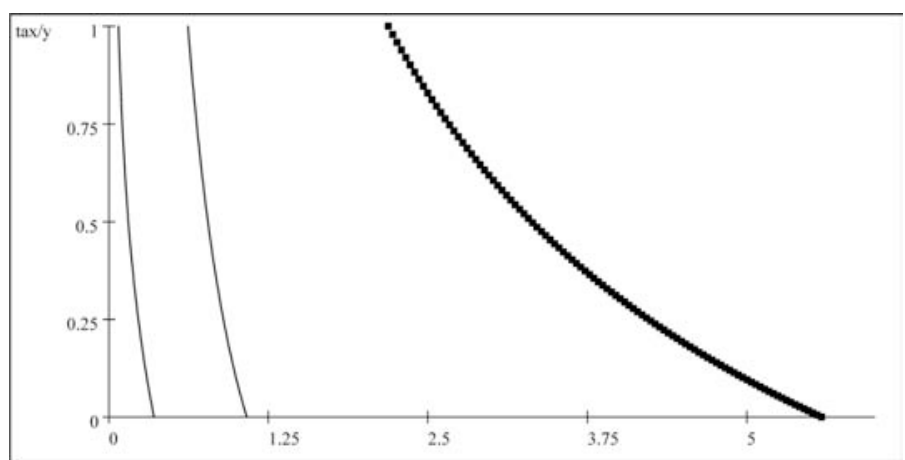

\section{Conclusion}

When private abatement depends on a trade-off between consumption and environment, individual engagement is not sufficient to find the optimal solution. Indeed, individual concerns are motivated by a purely selfish argument. Thus, the competitive equilibrium is inefficient for different configurations of capital stock and the environment. At a position of under-accumulation of capital and under-preservation of the environment, the increase in environmental taxation allows the competitive equilibrium to change toward the optimum by simultaneously increasing the quality of the envi- 
ronment and the capital stock. Depending on the relative effectiveness of public and private pollution-control technology, this change can take place by delegating abatement activities from the private sector to the public sector. On the other hand, if the economy is in a position of over-accumulation of capital and over-preservation of the environment, the government must reduce the level of savings in the economy along with the total level of abatement: in this case, public and private abatement change in a complimentary manner. Alternatively, an equilibrium initially characterized by asymmetrical inefficiencies, ie. over- (or under-) accumulation of capital and under- (or over-) preservation of the environment, leads all Paretoimproving reforms to a conflict between the economic and environmental benefits. In this last case, the policy of a tax earmarked for fighting pollution is irrelevant. It is therefore preferable to implement a more complex tax system, but take into consideration the set of economic distortions: providing a public good, externalities of pollution, and dynamic inefficiency. These results show that there is room for environmental policies and public abatement in the OECD countries since they are mostly characterized by over-accumulation of capital and under-preservation of the environment. But governments have to define their tax policies carefully in order to avoid conflicts between the environment and the economic growth.

\section{Bibliographie}

Beltratti A. (1995), "Growth with Natural and Environmental Resources", Working Paper E.E.E., No. 58.95, Fondazione Eni Enrico Mattei.

Bergstrom T.C., Blume L., Varian H. (1986), "On the Private Provision of Public Goods", Journal of Public Economics, vol. 33, pp. 25-49.

Bovenberg A.L., van der Ploeg F. (1994), "Environmental Policy, Public Finance and the Labour Market in a Second-best World", Journal of Public Economics, vol. 55, pp. 349-390.

Goulder (1995), "Environmental Taxation and the 'Double Dividend': A Reader's Guide," International Tax and Public Finance, vol. 2(2), pp. 271-297.

Gradus R., Smulders S. (1993), "The Trade-Off Between Environmental Care and LongTerm Growth-Pollution in Three Proto-type Models", Journal of Economics, vol. 58 , pp. $25-51$.

Ifen (2006), L'environnement en France, 2006, La Découverte.

Ifen (2005), L'économie de l'environnement en 2003, Rapport à la commission des comptes et de l'économie de l'environnement.

John A., Pecchenino R. (1994), "An Overlapping Generations Model of Growth and the Environment", The Economic Journal, vol. 104, pp. 1393-1410.

John A., Pecchenino R., Schimmelpfennig D., Schreft S. (1995), "Short-lived Agents and the Long-lived Environment", Journal of Public Economics, vol. 58, pp. 127-141. 
Jouvet, P.A., Michel P., Pestieau P. (2000), "Altruism, Voluntary Contributions and the Neutrality: the Case of Environmental Quality", Economica, vol. 67(268), pp. 465-475.

Jouvet, P.A., Michel P., Vidal J.P. (2000), "Intergenerational Altruism and the Environment", Scandinavian Journal of Economics, vol. 102(1), pp. 135-150.

Ligthart J.E., van der Ploeg F. (1996), "Optimal Government Policy, the Environment, Employment, and Tax Shifting", in Environmental Fiscal Reform and Unemployment, C. Carraro and D. Siniscalco Eds., Kluwer Academic Publishers, pp. 93-120.

Marini G., Scaramozzino P. (1995), "Overlapping Generations and Environmental Control", Journal of Environmental Economics and Management, vol. 29, pp. 64-77.

Michel P., Rotillon G. (1996), "Disutility of Pollution and Endogenous Growth", Environmental and Resource Economics, vol. 6, pp. 279-300.

OCDE (2006), Economie politique et taxes liées à l'environnement, OCDE Edition, Paris.

Ono T. (1996), "Optimal Tax Schemes and the Environmental Externality", Economics Letters, vol. 53(3), pp. 283-289.

van der Ploeg F., Withagen C. (1991), "Pollution Control and the Ramsey Problem", Environmental and Resource Economics, vol. 1, pp. 215-236.

Zhang J. (1999), "Environmental Sustainability, Nonlinear Dynamics and Chaos", Economic Theory, vol. 14, pp. 489-500. 